\title{
13
}

\section{RESPONSIBLY DESIGNING}

DIGITAL AGRICULTURE SERVICES

UNDER UNCERTAINTY IN

THE GLOBAL SOUTH

\section{The case of Esoko-Ghana}

Andy Bonaventure Nyamekye, Laurens

Klerkx, and Art Dewulf
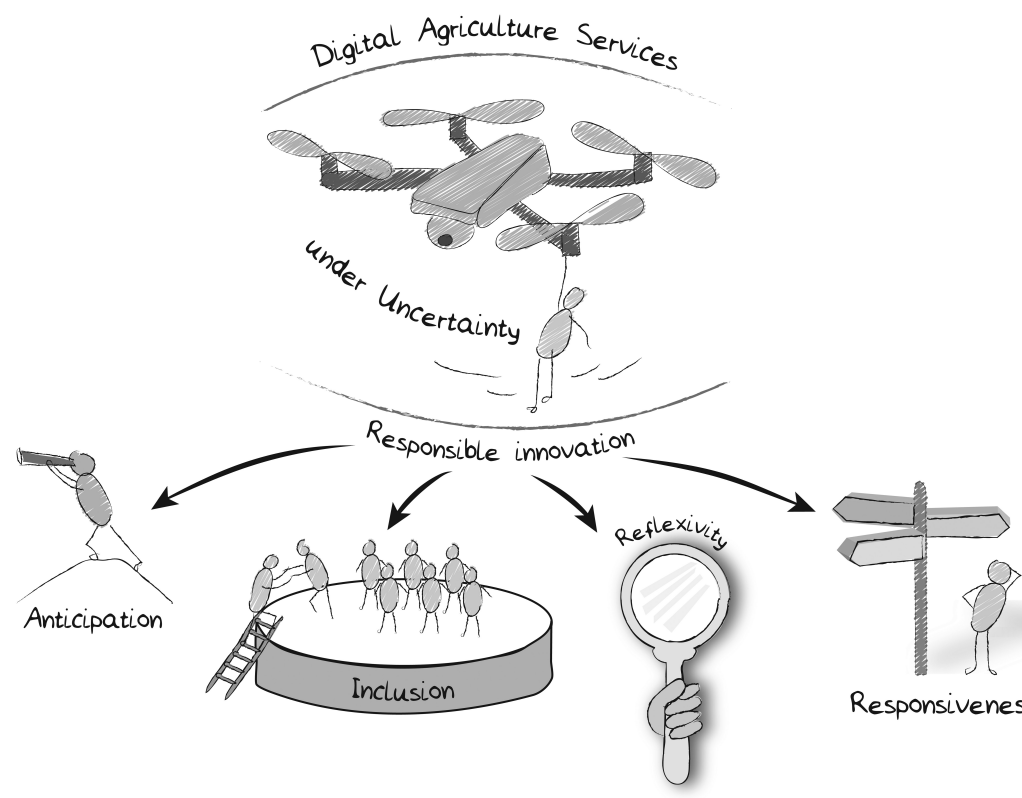

Responsiveness

\section{Introduction}

With the world population expected to reach close to 10 billion by 2050, innovation in African agriculture is a critical topic (Nelson et al., 2009, Barrett, 2020; Reardon et al., 2019; Hounkonnou et al., 2012). Innovations include new crop 
varieties, smart irrigation systems, drone technology, and blockchain and other internet-based solutions driven by mobile technology (Robertson et al., 2016; Wolfert et al., 2017; Shepherd et al., 2020), broadly captured under the banner of 'digital agriculture' (Klerkx et al., 2019). The agricultural sector in Africa is currently experiencing major transformation enabled by digital innovation. Digital services are expected to improve productivity in value chains, in the management of diseases, the efficient use of resources, and the reduction of labour. A surge in public and private enterprises in digital services is providing access to capital, market, weather, extension, and insurance services, mostly through mobile technology (Agyekumhene et al., 2020, Nyamekye et al., 2020, Evans, 2018, Munthali et al., 2018, Fabregas et al., 2019). Many of the proposed benefits of digital agriculture hinge on increased efficiency using precise mechanisation, automation, and improved decision-making. Digital agriculture has the potential to become a game changer in both the Global North and South; but it is also likely that resulting industry-wide digital transformation will create existential questions for agricultural stakeholders as they learn to grasp new ways of working (Barrett, 2020; Herrero et al., 2020; Klerkx and Rose, 2020; Reardon et al., 2019).

Both in the Global North and Global South — though perhaps a better distinction would be between high-income and low- and middle-income countriessuch issues have been noted regarding ethics, justice, and exclusion: for example in relation to data ownership and design of digital devices (Barrett, 2020; Fielke et al., 2020; Klerkx et al., 2019; Steinke et al., 2020), so that calls have been made for taking up responsibility in research and innovation (Bronson, 2018; Reardon et al., 2019; van der Burg et al., 2019). RRI is one of the recent frameworks projected to help address these challenges and to streamline innovation by ensuring a well-coordinated innovation process at regional, national, or subnational or organisational levels (De Saille, 2015; Lubberink et al., 2017; Owen et al., 2013; Von Schomberg, 2013).

RRI is underpinned by the argument that present modes of innovating with science and technology are unsuccessful because they fail to sufficiently account for social needs and values (Van Oudheusden, 2014). Furthermore, organisations and individuals innovate in environments characterised by uncertainties as a result of changes in social, economic, and environmental factors, even when these are accounted for (Klerkx et al., 2010; Meijer et al., 2006), and this has also been noted for digital agriculture (Bryant and Higgins, 2020; Eastwood and Renwick, 2020). The RRI framework is expected to help circumvent, eliminate, or manage such uncertainties (Pavie and Carthy, 2015; Tallacchini, 2014; Van Oudheusden, 2014). Furthermore, the RRI framework has now been applied in different national contexts (De Campos et al., 2017; De Hoop et al., 2016; Doezema et al., 2019; Macnaghten, 2020).

Recent literature has paid attention to how RRI principles can be applied to digital agriculture with a focus on high-income countries in Europe, North America, Australia, and New Zealand (Bronson, 2019; Eastwood et al., 2019; 
Fielke et al., 2020; Klerkx and Rose, 2020; Rose and Chilvers, 2018). Currently, the application of a framework such as RRI for the Global South (or low- and middle-income countries) is virtually non-existent, but rather concentrates on pockets of generic instruments aimed at strengthening institutions and guiding the innovative process at the country level (Oluwatobi et al., 2015; Sanginga et al., 2009). However, RRI is not always carried out as an organised and discrete process, but may also occur in a more loose or implicit fashion-at least in the early stages - and it remains to be seen how to best operationalise it in the different contexts where digital agriculture is developed (Bronson, 2019; Eastwood et al., 2019) by taking into account the particularities of the field (Rose and Chilvers, 2018).

This chapter focuses on Ghana, where Esoko (a social enterprise) has over the past 12 years provided digital services to farmers and value-chain actors. This includes the introduction of innovative products supported by digital technology amidst institutional, social, and economic changes which have consequences on their operations and services. The study sets out to establish the applicability of RRI framework elements under these conditions in Ghana: we explore how innovation occurs under uncertainty in social enterprises providing digital services to support actionable knowledge creation in food systems.

Nyamekye et al. (2020) in their study of food systems in northern Ghana define actionable knowledge as 'indigenous and scientific knowledge that is locally relevant, trustworthy, and produced in a fair, transparent way.' Whilst Nyamekye et al. approach the study from an actionable knowledge lens as outcome of digital agriculture services, this chapter attempts to unpack the black box of the process of responsible innovation towards digital agriculture services, rather than its outputs. Hence, we investigate how responsible innovation is organised under conditions of uncertainty by the target organisation.

\section{Theoretical framework and research methods: investigating responsible innovation in uncertain conditions}

Von Schomberg (2013, p. 19) defines RRI as a 'transparent, interactive process by which societal actors and innovators become mutually responsive to each other with a view to the (ethical) acceptability, sustainability and societal desirability of the innovation process and its marketable products (to allow a proper embedding of scientific and technological advances in our society).' Operationalising RRI as a governance framework, Stilgoe et al. (2013) mention four-dimensions: anticipation, responsiveness, reflexivity, and inclusion.

Anticipation prompts researchers and organisations to ask, 'what if ...?' questions, and to consider contingency, what is known, what is likely, what is plausible, and what is possible. Systematic thinking should shape the agenda of organisations. Anticipation requires foresight and forward-looking decisionmaking in an attempt to shape expected future states. In what the authors refer to as 'second-order' reflexivity, institutions should recognise the value systems 
(formal or informal) that define their innovation and governance systems. As innovation evolves, it could become essential to reflect on what values should be held, prioritised, or reformed. Responsiveness means that institutions as agents of innovation recognise the insufficiency of knowledge and control and can respond to new knowledge, perspectives, and norms. Inclusion involves embracing and drawing in multiple stakeholders through partnerships and different forms of collaboration in the innovation process.

Developing digital agriculture innovations happens in a complex and rapidly changing environment (Eastwood et al., 2017; Fielke et al., 2020), and this has implications for organisations (Rijswijk et al., 2019). This makes it critical to establish how the process of responsible innovation occurs within organisations in the face of uncertain developments and unknown futures. Uncertainties challenge organisations in how they deal with complex problems (Dewulf and Biesbroek, 2018; Klijn and Koppenjan, 2016). In establishing what objects of uncertainty arise, Klijn and Koppenjan highlight three objects of uncertainty: substantive, strategic, and institutional. Substantive uncertainty refers to uncertainty about the nature of a problem, its causal factors, and solutions. Strategic uncertainty refers to uncertainty about actors, their interests, and their strategies in engaging with each other; this could involve competition, collaboration, or coalition-building in achieving goals (Dewulf and Biesbroek, 2018). Institutional uncertainty refers to uncertainty about formal and informal rules of the game in the relevant network (Klijn and Koppenjan, 2016).

Uncertainty thus appears to be a challenge for organising RRI. For example, whilst Stilgoe et al. (2013) recognise institutional and cultural resistance to anticipation, such resistance could be due to institutional uncertainty about how formal and informal rules might evolve. Stilgoe et al. argue that institutional reflexivity holds the promise of self-awareness of lags and limits of knowledge about rules and how they could evolve. The inclusion dimension occurs in a condition of strategic uncertainty where organisations, as part of the governance process, have to deal with actor interests and varying ideas in deciding to compete, collaborate, or build coalitions. This makes the pursuit of an inclusive innovative process a high-risk endeavour under conditions of uncertainty (Dewulf and Biesbroek, 2018). About responsiveness, institutions' ability to change direction in response to stakeholder values and changing circumstances could occur under conditions of substantive uncertainty related to information-lack, incomplete, or conflicting-about problems they seek to address as innovative entities. Actors could also have different understandings of the problem being addressed.

Operators of digital agriculture services in the Global South, such as Esoko, can face these three objects of uncertainty, thus influencing the degree to which they can enact RRI in design and uptake of digital services (see Figure 13.1). Digital service providers are expected to enhance inclusive measures in their operations and service delivery. Engaging multiple actors also means being able to manage strategic uncertainty from collaborative arrangements and consultative processes. Similarly, adopting an anticipatory lens means they have the 


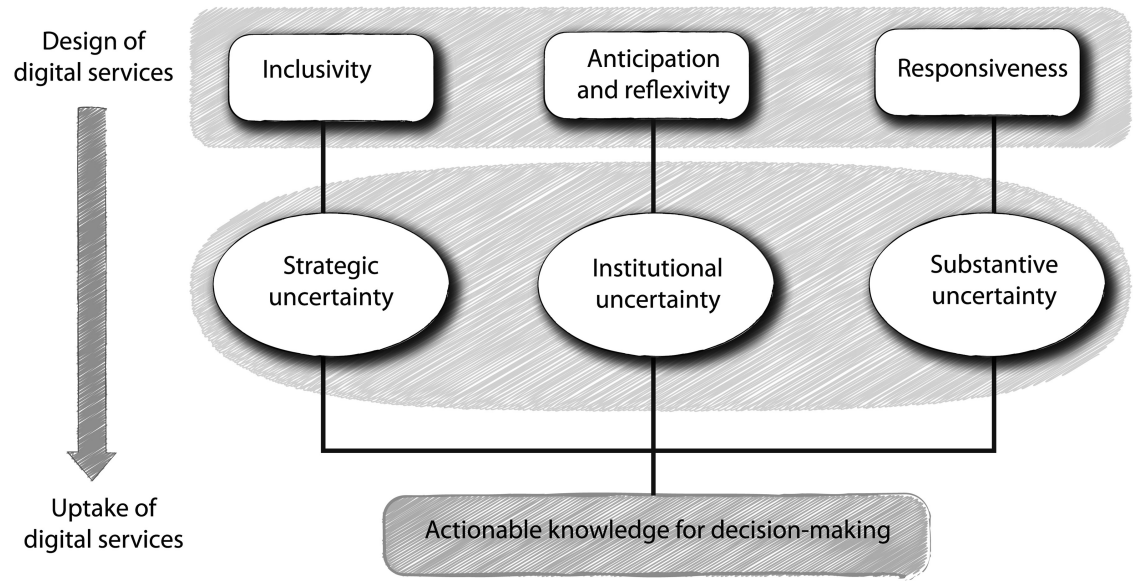

FIGURE 13.1 Conceptualising RRI in relation to design of digital services

ability to align digital innovation to a change in rules, to unpredictability in rules, and to how such transformation impact the innovation process. Hopefully, continuous reflexivity can accelerate instrumentation and strategy development in the governance of the innovative process to address institutional uncertainty in different forms. Accessing and leveraging agricultural data, information, and the translation of information into relevant knowledge whilst minimising substantive uncertainty also improves trust, reliability, and usability of knowledge produced. This is all, however, dependent on responsiveness in the innovation process.

Like Eastwood et al. (2019), we explore how the RRI framework can be made practical in digital agriculture services innovation-or what we will also refer to as responsible design, following Leeuwis et al. (2018). We specifically focus on the organisational level at Esoko.

Inaugurated in 2005 as Tradenet, Esoko was legally incorporated in Ghana with a vision to drive economic empowerment in rural areas by providing digital services. Headquartered in Ghana, the company has over the past years reached farmers in 20 countries with an established presence in Tanzania, Burkina Faso, Malawi, Zimbabwe, Benin, Cote d'Ivoire, Nigeria, and South Africa (See Figure 13.2). In Ghana, Esoko provides information services on market conditions, weather, cropping calendar, nutrition information, and agronomic advice to nearly 3.7 million rural inhabitants.

Our study of Esoko focused on how responsible innovation occurs under conditions of uncertainty in the design of digital services that enable actionable knowledge creation in food systems. The team designed semi-structured interview guides and engaged key staff of Esoko in Ghana. A total of 20 staff members were engaged, spanning technical, field, and administration units. ${ }^{1}$ Data was 


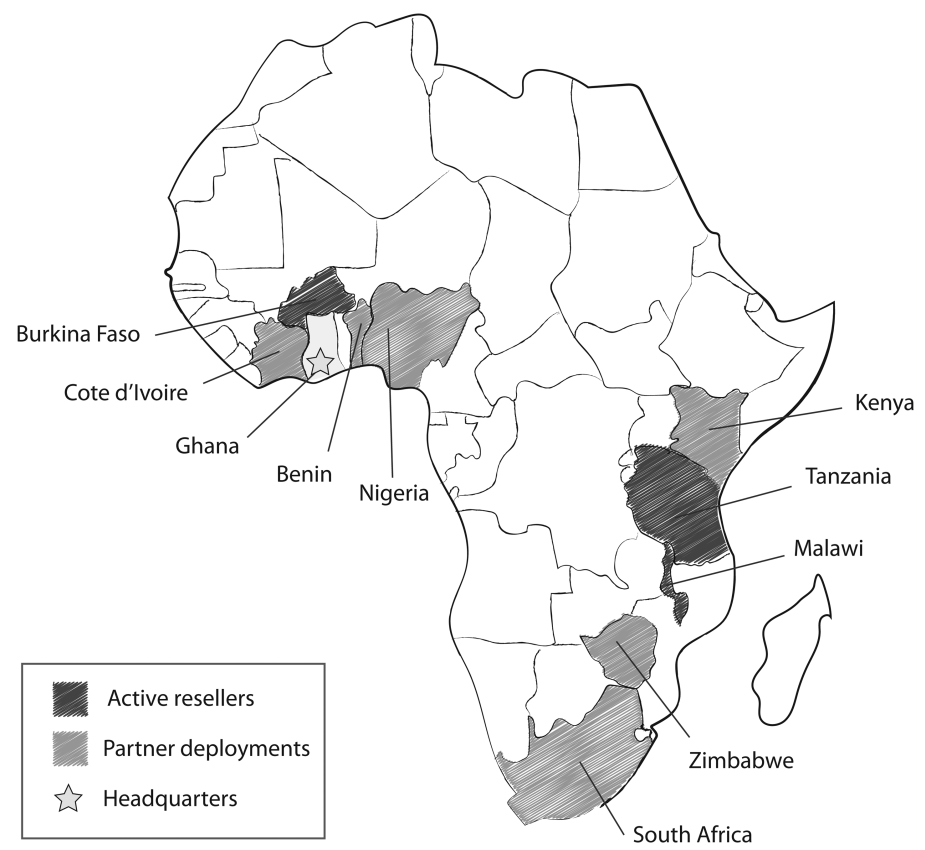

FIGURE 13.2 Geographical footprints of Esoko (2002-2020)

edited and processed, and a thematic analysis was undertaken to interpret the data, guided by the responsible innovation framework.

\section{Enabling inclusivity under strategic uncertainty}

Esoko's innovation process is guided by the so-called digital principles for sustainable development. ${ }^{2}$ Based on feedback from end-users of digital solutions, the technical team at Esoko go through an iterative process of redesigning the digital solutions. Although the feedback loop is a late end approach to inclusivity, the process of engaging end-users from the product design stage is expensive in terms of time and capital. End-users such as farmers, mostly in rural areas, are perceived to have low technical know-how required to support the design of digital services. Thus Esoko faces strategic uncertainty about the willingness and capability of actors to be included in the technology design process

Following Tongia and Subrahmanian (2006), iterative feedback cycles must be accounted for during the specification of solutions. Although Esoko has a number of internally designed policy instruments (Quality Assurance Policy, Equality and Diversity Policy, Environmental Policy, Health and Safety Policy, Grievance Procedure Policy), a pathway to inclusive design and scaling of digital solutions is yet to be tabled. The absence of a clear strategy or 'regulative 
configuration' (Steinke et al., 2020) for inclusivity in the presence of the adopted digital principles creates a vacuum where a tailor-made strategy would have increased the stepwise and incremental approach to success in uptake of digital solutions and of services rendered. This, however, is yet to be appreciated, as the following quote illustrates:

Esoko Operations Officer: Innovation is the foundation of Esoko. We always listen to our cherished customers and generate ideas to find solutions to their problems. To us, we innovate together with our customers because they introduce the problems and possible solutions to us.

Focusing on the external environment, Esoko is only required to satisfy regulations on data protection (Data Protection Act 2012-Act 843) enacted by the Parliament of Ghana in 2012 in the absence of a clear regulatory framework on digital agriculture-which are, however, emerging more broadly in recent times, e.g. Ayamga et al. (2020). Thus, before the enactment of the Data Protection Act, Esoko relied on internal ethical guidelines on data protection. Here, Esoko, like most enterprises set up before the enactment of the Data Protection Act, operated within a space of institutional uncertainty, with the interpretation of data protection limited to internal framing. Also, in the absence of a national framework on innovation in agriculture, the process of designing digital solutions is limited to the company's internal compliance measures informed by a list of international best practices deemed relatable to; a situation that an inclusive process could impact heavily towards creating responsible digital services that better contribute to actionable knowledge creation in food systems in which they are applied. Whilst Eastwood et al. (2019), Ortiz-Crespo et al. (2020), and Steinke et al. (2020) highlight strengthening user-centred design parameters for this purpose, Karpouzoglou et al. (2016), in their discussion of 'second generation' innovations, present co-creation and coordination as key elements for actor inclusivity.

Thus, the fair and transparent production of knowledge begins with a conscious, inclusive process of engaging end-users in responsible design. With the state as a regulator, the absence of regulatory frameworks could be compensated for by a consultative process where operators engage state regulatory institutions, who, all things being equal, seek to protect the masses from ethical and moral concerns associated with technology adoption in agriculture (van der Burg et al. 2019).

\section{Enabling anticipation and reflexivity under institutional uncertainty}

The study also set out to understand how uncertainty about rules challenges anticipation and reflexivity in the innovation process. From the study, we see a combination of anticipatory and reflexive processes being employed by Esoko. 
For example, following the deployment of digital solutions, market research is undertaken for feedback from end-users which is collated and presented by the marketing team to the product and operations team. Internal meetings are organised to discuss the relevance of feedback from the operations point of view. The product team then reports any relevant suggestions to the engineering team to ensure digital solutions are fit-for-purpose. Here, the enterprise uses a reflexive process to deal with informal rules in the user environment that were not anticipated. This allows the company to manage institutional uncertainty that is presented in the form of change in local conditions in user communities. The downside of this process, however, is the limited connection of the product review process to new debates in the digital landscape.

Esoko anticipates that rules on the operations of digital agriculture services might change across all levels of governance. For example, the buzz created by the government of Ghana concerning a digital economy might lead to the introduction of new rules in the near future. Furthermore, significant change is anticipated in conditions set by development agencies related to engaging private companies in programmes and project implementation in the fields of digital agriculture. However, until such changes are observed, anticipatory planning within the company is influenced strongly by end-user feedback.

Groves (2015), in referring to reflexive uncertainty and dealing with 'a double mind,' calls for an ex-ante approach in determining future responsibility, even though this is difficult when technological innovations are complex. As part of the prototyping and product development, Esoko could explore hypothetical scenarios to better establish existing uncertainties and new uncertainties that could arise. This includes addressing questions on usefulness and usability, with the logic that product innovation is not an end in itself but a continuous loop that must evolve as society evolves, or through forward decision-making (Bas and Guillo, 2015). In establishing a connection to actionable knowledge creation, the reflexive and anticipatory process enhances sharing, learning, and appreciation of rules and how they change, thereby enabling transparency and potential uptake and application of knowledge produced through user adoption of digital services.

\section{Enabling responsiveness under substantive uncertainty}

Part of Esoko's success hinges on its ability to minimise substantive uncertainty associated with information provided to end-users. For example, Esoko repackages weather forecasts from the Ghana Meteorological Agency and its partners as climate-smart agricultural information and channels it to farmers, extension officers, and water managers in its beneficiary communities. Esoko thus aims to inform farmer decisions on pre-season and in-season activities ranging from land preparation to harvesting. For the end-user, the accuracy of the forecast is crucial. The presence of a call centre at Esoko as a channel for direct interaction between farmers and experts helps manage ambiguities, misconceptions, and misinterpretation of forecast information. Farmers can also inquire directly 
TABLE 13.1 Summary of findings on improving innovation in social enterprises

\begin{tabular}{|c|c|c|c|}
\hline$R R I$ principle & Related uncertainty & Esoko's challenges & $\begin{array}{l}\text { Mechanisms to address } \\
\text { challenges }\end{array}$ \\
\hline Inclusivity. & $\begin{array}{l}\text { Strategic } \\
\quad \text { Uncertainty. }\end{array}$ & $\begin{array}{l}\text { Blurred } \\
\text { frameworks on } \\
\text { inclusion. }\end{array}$ & $\begin{array}{l}\text { Define co-creation and } \\
\text { coordination elements } \\
\text { for engaging actors } \\
\text { (Karpouzoglou et al., } \\
\text { 2016). } \\
\text { Strengthen user-centred } \\
\text { design parameters } \\
\text { (Eastwood et al., 2019, } \\
\text { Steinke et al., 2020). }\end{array}$ \\
\hline $\begin{array}{l}\text { Anticipation and } \\
\text { reflexivity. }\end{array}$ & $\begin{array}{l}\text { Institutional } \\
\text { uncertainty. }\end{array}$ & $\begin{array}{l}\text { Changes in } \\
\text { formal and } \\
\text { informal rules. }\end{array}$ & $\begin{array}{l}\text { Adopt a forward-looking } \\
\text { decision-making approach } \\
\text { (Bas and Guillo, 2015). }\end{array}$ \\
\hline Responsiveness. & $\begin{array}{l}\text { Substantive } \\
\text { Uncertainty. }\end{array}$ & $\begin{array}{l}\text { Information } \\
\text { asymmetry } \\
\text { and lack } \\
\text { thereof. }\end{array}$ & $\begin{array}{l}\text { Adopt citizen science } \\
\text { approaches (Cieslik et al., } \\
\text { 2017; Munthali et al., } \\
\text { 2018). } \\
\text { Integrate different } \\
\text { knowledge systems in } \\
\text { information framing } \\
\text { (Nyadzi et al., 2019). }\end{array}$ \\
\hline
\end{tabular}

before receiving information on their mobile phones. The responsive process enabled by the call centre helps manage differences in framing, expectations, and trust.

Following Agyekumhene et al. (2020), however, the pursuit of trust and information symmetry on the side of service providers could be counterproductive given that farmers, due to limited inclusiveness in design, interpret this as surveillance and control. Also, Nyadzi et al. (2019) point to knowledge integration in dealing with substantive uncertainty due to information asymmetry. Nyadzi et al. confirm findings of enhanced trust for weather and seasonal information among farmers in northern Ghana when scientific and indigenous knowledge is integrated (see Table 13.1).

\section{Conclusion}

The RRI framework holds promise to support responsible innovation in digital agriculture now and in the future. Whilst appreciating its significance, this study nevertheless argues that an extension of the framework to digital service provision in Ghana, using Esoko as a case study, can be challenging given the existing strategic, institutional, and substantive uncertainty. Firstly, in the context of poor regulatory and policy frameworks around digital agriculture, the 
RRI framework would be challenging to implement 'to the letter,' mainly due to strategic uncertainties with potential impact on inclusive design of digital services. The RRI framework must therefore be weighted with the state of strategic governance and the degree to which governance parameters serve as enablers. Secondly, changes in rules-just as much as their absence-shape practices and have consequences on the adoption of digital services, which are pertinent to reflexivity and anticipation in responsible innovation. Lastly, in contexts where unfavourable environmental and climatic conditions pose uncertainties with consequences on information provision, responsiveness in providing digital services could be hampered.

These uncertainties indicate as yet a limited 'readiness' to enact RRI in the setting that was analysed; this resembles the point made by Eastwood et al. (2019) that RRI, in settings where there is limited experience applying it, is initially patchy. In view of these uncertainties, as discussed by Rose and Chilvers (2018) and Bronson (2019), an RRI rubric for digital agriculture is needed. Such a rubric could not only foster the goals of reflexivity and inclusion in digital agriculture in the Global North where RRI has been mostly applied as a concept to support digital agriculture innovation, but also in North-South collaborations in the digital agriculture space. This would require due attention to making RRI locally applicable and culturally sensitive (Doezema et al., 2019; Klerkx et al., 2019; Macnaghten et al., 2014): in view of the global political economy of digital agriculture (Clapp and Ruder, 2020; Rikap and Lundvall, 2020), RRI in this case would need to increase attention to power dimensions and dependency relationships.

\section{Notes}

111 Technical Officers, 8 Market Enumerators and 1 Operations Officer.

2 These principles have been endorsed by over 54 international organisations led by the United States Agency for International Development. See: https://digitalprinciples .org/.

\section{References}

Agyekumhene, C., De Vries, J., Paassen, A. V., Schut, M. and Macnaghten, P. (2020). Making smallholder value chain partnerships inclusive: Exploring digital farm monitoring through farmer friendly smartphone platforms. Sustainability, 12, 4580.

Ayamga, M., Tekinerdogan, B., Kassahun, A., \& Rambaldi, G. (2021). Developing a policy framework for adoption and management of drones for agriculture in Africa. Technology Analysis \& Strategic Management. 33(8), 970-987.

Barrett, C. B. (2020). Overcoming global food security challenges through science and solidarity. American Journal of Agricultural Economics. Early view, available online. https://doi.org/10.1111/ajae.12160

Bas, E. and Guillo, M. (2015). Participatory foresight for social innovation. FLUX-3D method (Forward Looking User Experience), a tool for evaluating innovations. Technological Forecasting and Social Change, 101, 275-290. 
Bronson, K. (2018). Smart farming: Including rights holders for responsible agricultural innovation. Technology Innovation Management Review, 8, 7-14.

Bronson, K. (2019). Looking through a responsible innovation lens at uneven engagements with digital farming. NJAS-Wageningen Journal of Life Sciences, 90, 100294.

Bryant, M. and Higgins, V. (2020). Securitising uncertainty: Ontological security and cultural scripts in smart farming technology implementation. Journal of Rural Studies, 81, 315-323.

Clapp, J. and Ruder, S.-L. (2020). Precision technologies for agriculture: Digital farming, gene-edited crops, and the politics of sustainability. Global Environmental Politics, 20, 49-69.

De Campos, A. S., Hartley, S., De Koning, C., Lezaun, J. and Velho, L. (2017). Responsible innovation and political accountability: Genetically modified mosquitoes in Brazil. Journal of Responsible Innovation, 4, 5-23.

De Hoop, E., Pols, A. and Romijn, H. (2016). Limits to responsible innovation. Journal of Responsible Innovation, 3, 110-134.

De Saille, S. (2015). Innovating innovation policy: The emergence of 'Responsible Research and Innovation'. Journal of Responsible Innovation, 2, 152-168.

Dewulf, A. and Biesbroek, R. (2018). Nine lives of uncertainty in decision-making: strategies for dealing with uncertainty in environmental governance. Policy and Society, 37, 441-458.

Doezema, T., Ludwig, D., Macnaghten, P., Shelley-Egan, C. and Forsberg, E.-M. (2019). Translation, transduction, and transformation: Expanding practices of responsibility across borders. Journal of Responsible Innovation, 6, 323-331.

Eastwood, C., Klerkx, L., Ayre, M. and Rue, B. D. (2019). Managing socioethical challenges in the development of smart farming: From a fragmented to a comprehensive approach for responsible research and innovation. Journal of Agricultural and Environmental Ethics, 32, 741-768.

Eastwood, C., Klerkx, L. and Nettle, R. (2017). Dynamics and distribution of public and private research and extension roles for technological innovation and diffusion: Case studies of the implementation and adaptation of precision farming technologies. Journal of Rural Studies, 49, 1-12.

Eastwood, C. and Renwick, A. (2020). Innovation uncertainty impacts the adoption of smarter farming approaches. Frontiers in Sustainable Food Systems, 4(24), 1-14.

Evans, O. (2018). Digital agriculture: Mobile phones, internet \& agricultural development in Africa. Actual Problems of Economics, 7/8(205/206), 76-90.

Fabregas, R., Kremer, M. and Schilbach, F. (2019). Realizing the potential of digital development: The case of agricultural advice. Science, 366.

Fielke, S., Taylor, B. and Jakku, E. (2020). Digitalisation of agricultural knowledge and advice networks: A state-of-the-art review. Agricultural Systems, 180, 102763.

Groves, C. (2015). Logic of choice or logic of care? Uncertainty, technological mediation and responsible innovation. NanoEthics, 9, 321-333.

Herrero, M., Thornton, P. K., Mason-D'croz, D., Palmer, J., Benton, T. G., Bodirsky, B. L., Bogard, J. R., Hall, A., Lee, B. and Nyborg, K. (2020). Innovation can accelerate the transition towards a sustainable food system. Nature Food, 1, 266-272.

Hounkonnou, D., Kossou, D., Kuyper, T. W., Leeuwis, C., Nederlof, E. S., Röling, N., Sakyi-Dawson, O., Traoré, M. and Van Huis, A. (2012). An innovation systems approach to institutional change: Smallholder development in West Africa. Agricultural Systems, 108, 74-83.

Karpouzoglou, T., Zulkafli, Z., Grainger, S., Dewulf, A., Buytaert, W. and Hannah, D. M. (2016). Environmental virtual observatories (EVOs): Prospects for knowledge 
co-creation and resilience in the information age. Current Opinion in Environmental Sustainability, 18, 40-48.

Klerkx, L., Aarts, N. and Leeuwis, C. (2010). Adaptive management in agricultural innovation systems: The interactions between innovation networks and their environment. Agricultural Systems, 103, 390-400.

Klerkx, L., Jakku, E., \& Labarthe, P. (2019). A review of social science on digital agriculture, smart farming and agriculture 4.0: New contributions and a futureresearch agenda. NJAS-Wageningen Journal of Life Sciences. 90-91, 100315.

Klerkx, L. and Rose, D. (2020). Dealing with the game-changing technologies of Agriculture 4.0: How do we manage diversity and responsibility in food system transition pathways? Global Food Security, 24, 100347.

Klijn, E.-H. and Koppenjan, J. (2016). The shift toward network governance. In: de Walle, S. and Groeneveld, S. (eds.). Theory and practice of public sector reform. Milton Park: Routledge, 158-177.

Leeuwis, C., Cieslik, K., Aarts, M., Dewulf, A., Ludwig, F., Werners, S. and Struik, P. (2018). Reflections on the potential of virtual citizen science platforms to address collective action challenges: Lessons and implications for future research. NJASWageningen Journal of Life Sciences, 86, 146-157.

Lubberink, R., Blok, V., Van Ophem, J. and Omta, O. (2017). A framework for responsible innovation in the business context: Lessons from responsible-, social-and sustainable innovation. Responsible Innovation, 8, 181-207.

Macnaghten, P. (2020). The making of responsible innovation. Cambridge: Cambridge University Press.

Macnaghten, P., Owen, R., Stilgoe, J., Wynne, B., Azevedo, A., De Campos, A., Chilvers, J., Dagnino, R., Di Giulio, G. and Frow, E. (2014). Responsible innovation across borders: Tensions, paradoxes and possibilities. Journal of Responsible Innovation, 1, 191-199.

Meijer, I. S., Hekkert, M. P., Faber, J. and Smits, R. E. (2006). Perceived uncertainties regarding socio-technological transformations: Towards a framework. International Journal of Foresight and Innovation Policy, 2, 214-240.

Munthali, N., Leeuwis, C., Van Paassen, A., Lie, R., Asare, R., Van Lammeren, R. and Schut, M. (2018). Innovation intermediation in a digital age: Comparing public and private new-ICT platforms for agricultural extension in Ghana. NJAS-Wageningen Journal of Life Sciences, 86, 64-76.

Nelson, G. C., Rosegrant, M. W., Koo, J., Robertson, R., Sulser, T., Zhu, T., Ringler, C., Msangi, S., Palazzo, A. and Batka, M. (2009). Climate change: Impact on agriculture and costs of adaptation. International Food Policy Research Institute.

Nyadzi, E., Werners, E. S., Biesbroek, R., Long, P. H., Franssen, W. and Ludwig, F. (2019). Verification of seasonal climate forecast toward hydroclimatic information needs of rice farmers in Northern Ghana. Weather, Climate, and Society, 11, 127-142.

Nyamekye, A. B., Dewulf, A., Van Slobbe, E. and Termeer, K. (2020). Information systems and actionable knowledge creation in rice-farming systems in Northern Ghana. African Geographical Review, 39, 144-161.

Oluwatobi, S., Efobi, U., Olurinola, I. and Alege, P. (2015). Innovation in Africa: Why institutions matter. South African Journal of Economics, 83, 390-410.

Ortiz-Crespo, B., Steinke, J., Quirós, C. F., van de Gevel, J., Daudi, H., Gaspar Mgimiloko, M., \& van Etten, J. (2020). User-centred design of a digital advisory service: Enhancing public agricultural extension for sustainable intensification in Tanzania. International Journal of Agricultural Sustainability, 1-17. Online first, https:// doi.org/10.1080/14735903.2020.1720474 
Owen, R., Bessant, J. R. and Heintz, M. (2013). Responsible innovation: Managing the responsible emergence of science and innovation in society. New York: John Wiley \& Sons.

Pavie, X. and Carthy, D. (2015). Leveraging uncertainty: A practical approach to the integration of responsible innovation through design thinking. Procedia-Social and Behavioral Sciences, 213, 1040-1049.

Reardon, T., Echeverria, R., Berdegué, J., Minten, B., Liverpool-Tasie, S., Tschirley, D. and Zilberman, D. (2019). Rapid transformation of food systems in developing regions: highlighting the role of agricultural research \& innovations. Agricultural Systems, 172, 47-59.

Rijswijk, K., Klerkx, L. and Turner, J. A. (2019). Digitalisation in the New Zealand agricultural knowledge and innovation system: Initial understandings and emerging organisational responses to digital agriculture. NJAS-Wageningen Journal of Life Sciences, 90, 100313.

Rikap, C. and Lundvall, B.-Å. (2020). Big tech, knowledge predation and the implications for development. Innovation and Development. Online first, https://doi.org/10.1080/2 157930X.2020.1855825.

Robertson, M., Kirkegaard, J., Rebetzke, G., Llewellyn, R. and Wark, T. (2016). Prospects for yield improvement in the Australian wheat industry: a perspective. Food and Energy Security, 5, 107-122.

Rose, D. C. and Chilvers, J. (2018). Agriculture 4.0: Broadening responsible innovation in an era of smart farming. Frontiers in Sustainable Food Systems, 2, 87.

Sanginga, P. C., Waters-Bayer, A., Kaaria, S., Wettasinha, C. and Njuki, J. (2009). Innovation Africa: enriching farmers' livelihoods. London: Earthscan.

Shepherd, M., Turner, J. A., Small, B. and Wheeler, D. (2020). Priorities for science to overcome hurdles thwarting the full promise of the 'digital agriculture' revolution. Journal of the Science of Food and Agriculture, 100, 5083-5092.

Steinke, J., Van Etten, J., Müller, A., Ortiz-Crespo, B., Van De Gevel, J., Silvestri, S. and Priebe, J. (2020). Tapping the full potential of the digital revolution for agricultural extension: an emerging innovation agenda. International Journal of Agricultural Sustainability, 1-17, DOI: 10.1080/14735903.2020.1738754

Stilgoe, J., Owen, R. and Macnaghten, P. (2013). Developing a framework for responsible innovation. Research Policy, 42, 1568-1580.

Tallacchini, M. (2014). Between uncertainty and responsibility: Precaution and the complex journey towards reflexive innovation. In: Van Asselt, M. B. A., Everson, M. and Vos, E. (eds.). Trade, Health and the Environment: The European Union put to the test. Earthscan, 74-88.

Tongia, R. and Subrahmanian, E. (2006) Information and Communications Technology for Development (ICT4D). A design challenge? International Conference on Information and Communication Technologies and Development, 200, IEEE, 243-255.

Van Der Burg, S., Bogaardt, M.-J. and Wolfert, S. (2019). Ethics of smart farming: Current questions and directions for responsible innovation towards the future. NJAS-Wageningen Journal of Life Sciences, 90, 100289.

Van Oudheusden, M. (2014). Where are the politics in responsible innovation? European governance, technology assessments, and beyond. Journal of Responsible Innovation, 1, 67-86.

Von Schomberg, R. (2013). A vision of responsible innovation. In: Owen, R., Heintz, M. and Bessant, J. (eds.). Responsible Innovation. Hoboken: John Wiley.

Wolfert, S., Ge, L., Verdouw, C. and Bogaardt, M.-J. (2017). Big data in smart farming-a review. Agricultural Systems, 153, 69-80. 